\title{
Research Summary of Yao Dance in Guangdong
}

\author{
Yong Zhao \\ Guangdong Shaoguan University; Shaoguan 512000 China
}

Keywords: Guangdong; Yao Dance; Research Review.

\begin{abstract}
There are a large number of ethnic minorities in China, and it is a harmonious development of multi-ethnic groups. The Yao nationality in Guangdong has a long history and a distinctive national culture, and its folk dance has attracted much attention. To do a good job in the transmission of Yao dance is conducive to the development and inheritance of its national culture. This paper from four aspects as follows: the development history of Yao dance in Guangdong, heritage value, creative situation and creative development, will make a brief summary and put forward some suggestions to inherit the Yao dance.
\end{abstract}

\section{Introduction}

The Yao dance in Guangdong rooted in local cultural customs is advocating simple and free expression. It is an important recreation tool for the local people and also an expression of its spiritual content. The audience from the experience of the Yao nationality cherishing their ancestors' abundant humanistic feelings can also see the Yao nationality's expectation for a better life that has a favorable weather and have a broad understanding of the cultural connotation of the Yao. The excavation and utilization of this art form is conducive to the unity among the nationalities, and has left an important intangible heritage for our country's cultural treasures. Here is a brief study of Yao dance.

\section{The Summary of Yao Dance in Guangdong}

The most densely distributed areas in Guangdong are the two autonomous counties of Liannan and Ruyuan. The geographical environment of the two countries is very bad. High mountains and lofty hills hinder economic development, and also restricts the integration of local culture and foreign culture. Therefore, the Yao dance is better preserved as its spiritual entertainment carrier. Moreover, the local cultural heritage is better with the fusion of dance more closely, and its songs and dances have strong national characteristics. There is a legend that Yao dance is for the son of the king that made drums to commemorate his father. He will make the wild goat that killed his father peeling and empty dove tree into long drum, and knock it to comfort the spirit of his deceased father. Later, it gradually developed into a kind of sacrifice, and then the celebration of folk festivals. At present, the main Yao dance are long drum dance and copper drum dance and so on, and its important tools of dance performance has drums. According to the time of its large-scale dance, it can be divided into two types: sacrificial ceremony and festival type. The Yao dance is rooted in the local traditional culture and has the following characteristics.

\subsection{The Perfect Fusion of Dance and Drum Music}

From the beginning of the creation of Yao dance, to the important stage of today's inheritance, Yao dance and drum music can not be divided. Drum music is a kind of strong folk music form, combined with the Yao dance, through the beat rhythm to create a good atmosphere of dance environment, and enhance the performance of dance. In this process, the local Yao culture was presented perfectly, not only to meet the Yao people's expression of desired and self-entertainment needs, but also for visitors to show the fancy of Yao culture, leaving beautiful and exquisite cultural heritage for our country.

\subsection{Rich in Content and Strong in Emotion}

Yao dance is mainly in sacrifice and festivals, which can be seen that it is an art form with local residents' strong and colorful emotion. On the one hand, it shows the Yao people' feelings of recalling their ancestors; on the other hand, it reflects the Yao people having the festival joyful and longing for 
a better life. Yao's development is relatively more closed, less cultural exchanges, and the dance structure is more single, so its emotions are extremely strong that the audience can directly feel the dancers' inner feelings. In addition, the integration of Yao dance and daily life is pretty high, so its content is not restricted. The more wonderful the life, the more colorful the dance. Through the artistic creation of these content using the streamlining of dance activities for enrichment, is the main source of Yao dance creation.

\subsection{The Ideas Are Unique and the form Is Flexible}

The Yao dance emphasizes the development of individuality, and advocates the liberation of nature, the freedom of bondage and the freedom of art. These dance movements are the aspirations of the people. For example, the content of copper drum is unrestrained, focusing on an outlet for emotions. It reflects the wishes of the Yao people to return to nature. In addition, Yao dance has less restrictions on movement, so dancers can show their personality and its forms are also vivid and colorful.

\section{Inheritance Value of Yao dance}

\subsection{Artistic Merit of Yao Dance}

The folk Yao dance has great artistic attainments. Its strong national characteristics represent the essence of the Yao nationality's art and are of great significance to the inheritance and development of dance art. With its lasting charms, the development of the Yao nationality's dance has occupied a pretty important position in the aboriginal dance field.

\subsection{Cultural Value of Yao Dance}

The various-stage features of Yao dance have vividly revealed development and transition of the Yao nationality culture. As a protector of national unity and harmony, this folk dance has brought local people closer together and enhanced their identity and cohesion. In addition, the dance can be a window of local culture and customs, through which we are able to strengthen our ethnic unity.

\subsection{Economic Value of Yao Dance}

Attracting a large number of tourists with its artistic beauty, the traditional dance has promoted the development of local tourism and economy in the agglomeration of the Yao nationality. It should be noted that the protection of national culture is crucial. On the other hand, try to avoid the impact of foreign culture, which may cause serious damages to the dance culture of the Yao nationality. Economic and cultural developments are mutually reinforcing each other rather than contradictory as long as they are properly used.

\subsection{Artistic Beauty of Yao Dance}

The dance movements of the Yao nationality are highly compatible with nature, expressing its unique artistic beauty.

1.Beauty of folk culture. The folk Yao dance is inspired by daily life and its lively dance moves express the hospitality of local people. By applying dance moves of strong local color and wearing special costumes, such as those in hunting, the dancing has demonstrated the industry and simplicity of local people. The use of traditional costumes has enhanced artistic expressive force of dance and strengthened the resonance between audience and dancers, revealing the beauty of folk custom.

2. Beauty of dance movement. Inspired by the great nature, creators of the folk dance had expressed their daily life by designing grace and coherent dance movements. Take the long drum dance for example. Performers are dancing with long drums fitting their bodies closely, enhancing coherences of movements and long drum dance is considered to be a classic creature of Yao nationality's aesthetic attainments. The bronze-drum dance is another example, whose dance movements are created by imitating those of monkeys, especially the imitation of their squat and run. The performance of bronze-drum dance is intended to demonstrate their lovely life attitudes and advocation of simple nature. These graceful movements are considered to be an important heritage of both dance and folk culture of the Yao nationality.

3. Beauty of local religion. The folk Yao dance is a platform to reveal their local religion and that' s so-called----"Art comes from life, and is superior to life". For example, the sacrificial dance is a mirror of their firm faith, which reflects people's pursuit of a better life. What's more, the particular 
dance movements and costumes, highly compatible with nature, are aimed at expressing their respect of nature. Through perfect presentation and appeal of the belief, local people's life attitude is becoming more and more positive, which is also the goal of sacrifice.

\section{Current Creating Situation of Guangdong Yao dance}

The development of Yao dance in Guangdong province has been paid more and more attention. A lot of Yao dance forms are classified as intangible cultural heritage, and economic development also drove the spread of local culture. In addition to the traditional dance, expanding the content to enhance its artistic value and expressiveness is also very important. At present, the creation of Yao dance mainly faces the following problems.

\subsection{The Distorted Expression in Artistic Form}

Even though the creation of works and content is increasing, the Yao's own expressiveness in artistic form is getting weaker. First of all, some dance creation on the Yao dance action has wrong emphasis. They focus on the expression of some gorgeous, gimmicky movements, such as rotation, but do not pay enough attention to the inherent spirit of the Yao dance. For example, the original Yao dance, with leg strength and being close to nature, shows a kind of admiration of nature, struggling to get out of shackles, but these spirit do not be reflected in a large number of gaudy dance moves. This aesthetic distortion is a manifestation of the choreographers' quick success attitude. Secondly, the original Yao dance is far away from the spirit connotation of original Yao dance in the content selection (being close to nature, longing to a better life). In some of the new dance, it emphasizes too much on theory and the use of new elements, leading to the hit to the quaintness of its original content, and a serious weakening on its cultural expression. Finally, there are some works separating from the national cultural logic in the structure. Since Guangdong Yao dance is derived from life, it is a performance of folk culture, while some creations only lay emphasis on the external structure of the performance, such as double dance, so that ignoring the nature of structural performance. This phenomenon is generally created by the choreographers' lack of understanding on Yao culture and its folk customs.

\subsection{Non-Obviousness of Ethnic Style of Yao Nationality}

Yao's traditional dance has a strong ethnic color, while some choreographers' lack of understanding or ignorance of Yao culture will lead to non-obviousness of ethnic style, which is not only conductive to its artistic value, expressiveness, but also to the role of dance in inheriting Yao ethnic culture. On the one hand, the extensive use of western elements results in the disappearance of the original of the ethnic dance, on the other hand, the wrong expression of folk culture will affect the audience's aesthetic experience, misleading the audience appreciation of Yao culture. First of all, it is the choreographer's lack of understanding of the Yao culture (folklore, development of history, social style, etc.) that causes the disappearance of ethnic style. Secondly, the unreasonable fusion of western elements in some choreographers with quick success attitude leads to distortion of its ethnic attributes.

\section{The Creation Development of Yao Dance in Guangdong Province}

\subsection{Enhance Personalization to Show National Connotation}

Concerning with the strong ethnic flavor of Yao dance, we need to strengthen its personalized expression, focus on its life style of advocating nature and loving freedom. On the one hand, the choreographer should study the spirit of the Yao people's culture in depth and integrate it into the dance. On the other hand, they should consider the spiritual needs and ideological beliefs of the modern Yao people, and set them as the direction of artistic creation.

\subsection{Absorb Multicultural to Enrich Performance Content}

With the speeding-up development of globalization, more and more cultures achieve the integration of innovation, while Guangdong Yao culture, with its narrow spread, has less competitiveness. Therefore, on the one hand we need to do well the protection, to avoid serious impact of foreign culture, which requires the people of Yao and other ethnic groups to work together; on the 
other hand, the selective absorption of foreign cultures is also needed because ethnic culture itself demands development. Therefore, taking the initiative to carry out cultural exchanges can effectively control the direction of cultural development, to avoid cultural destruction. For example, for the development of Panwang festival of Yao minority, changes in form can be made by using scientific and technological elements to show its ancient spirit in a more intuitive way. We should pay attention to the selection of foreign culture, and to choosing the essence during multi-cultural integration.

\section{Inheritance Strategy of Yao Dance of Guangdong}

\subsection{Strengthen the Cooperation of Different Areas}

The distribution of Yao nationality in Guangdong district is relatively disperse, and the culture among different areas also has difference and different advantages. In the traditional culture development progress, the repulsive force of different areas is relatively great, which makes the development of Yao nationality lagging. In order to change the current situation, the communication of different areas needs to be strengthened. On the one hand, make the resource integration and improve its development efficiency on the basis of maintaining certain independence; on the other hand, recommend the representative people to make the communication and cooperation using the spot to bring the surface to strengthen mutual identifying sense.

\subsection{Innovated Development Facing to the World}

Globalization has brought enormous impact and challenge as well as greater opportunity to the development of Yao dance. On the one hand, it should be protected from too big impact and positively integrate into the world stage. For example, increasing the times to perform aboard, improve the expression and attraction, etc. It needs to be emphasized that this action is established on the basis of national culture inheritance, promoting its culture competitiveness not simply distorting the spirit content for the globalization. On the other hand, the development area of Yao dance should be expanded. At first, the government should make the integration and application with the publicity resource; next, the input intensity of capital should be augmented; at last, the training plan of relevant talents should be implemented early to inject new vitality to its development.

\section{Conclusion}

Through the study of this paper, we have primarily learned Yao dance and discussed the important value and main approach to inherit its cultural spirit. When promoting Yao dance, the related staffs must do the protection work of its cultural content, and the phenomenon of separating Yao culture even distorting its art expression pattern because of seeking quick success and instant benefits should be eradicated. First of all, we must deeply learn the folk culture and development history of Yao nationality, making the deep digging with the inner spirit of its dance; then combine with the multiculture to compose the work that meets the spirit demand of current Yao people and expresses the original spirit; in the end, making promotion with these pieces in reasonable method, enhance the cognition of inner Yao nationality to its culture and close the relation among other nationalities and Yao to promote the development of harmonious big family. The spread and protection with its art pattern also leave precious cultural inheritance for the offspring.

\section{Acknowledgments}

Interdisciplinary Construction Youth Program by "13th Five-Year" Planning by Philosophy and Social Science of Guangdong Province: "Contemporary Excavation and Utilization Based on National Traditional Dance Resources--Study on Dance Elements of Yao Nationality in North Guangdong" (No.GD16XYS32)

Initial Results of Longitudinal Academic Research Project by Shaoguan University, 2015: "Collection, Analysis and Application of Stage Editing of Dance Elements of Yao Nationality in Ruyuan” (No. S201502023) 


\section{References}

[1]. Kai Wang. The prop application and image creation of Yao dance [J]. Theatrical family, 2016, (23):132.

[2]. Yanmin Chen. The creating current situation and some thinking with Liannan Yao dance [J]. Public literature, 2016, (18):163.

[3]. Liang Sun. The exploration of Yao traditional dance art-taking the bronze drum dance as example [J]. Big stage, 2015, (09):146-147.

[4]. Yong Zhao. The analysis and thinking of creating current situation of Liannan Yao dance of Guangdong [J]. Yihai, 2014, (05):141-142.

[5]. Dongyun Chen. The protection and education inheritance of Yao traditional dance [D]. Guangxi Normal University, 2012. 